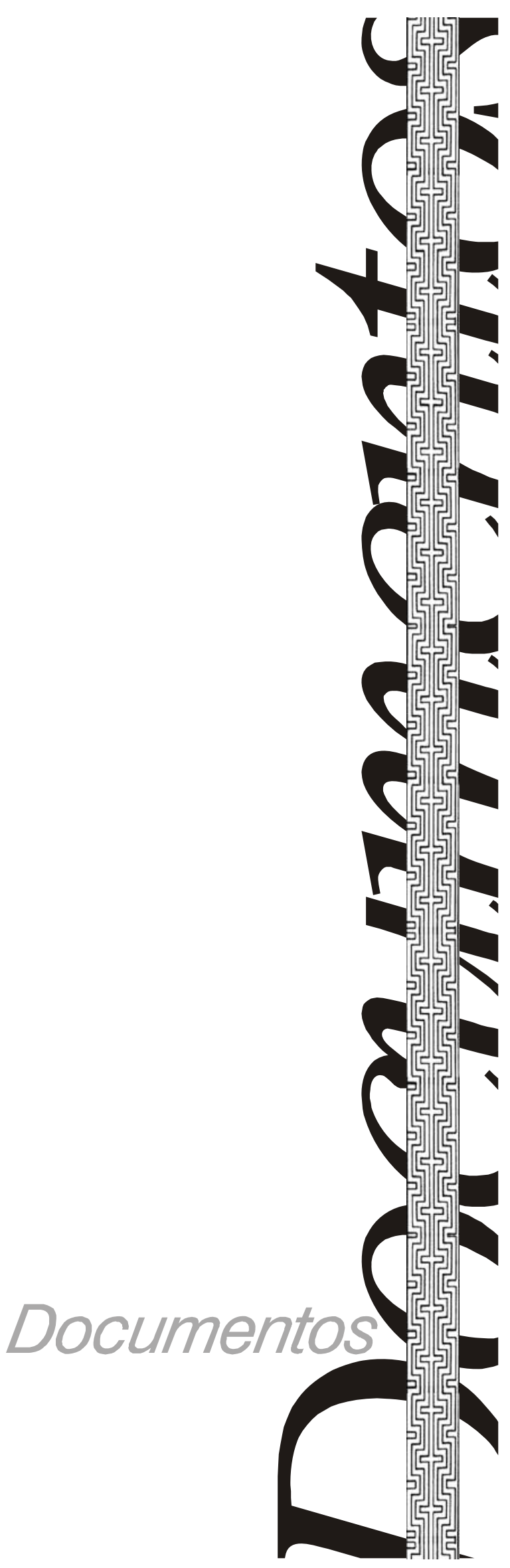





\title{
Conflito e violência no território dos Kaiowá/Guarani
}

\author{
Eva Maria Luiz Ferreira* \\ Antônio Brand**
}

\section{Introdução}

A História contemporânea dos índios Kaiowá e Guarani no sul do então estado de Mato Grosso, vem marcada por conflitos e violências relacionadas à posse de seu território tradicional. A documentação do período traz importantes informações sobre esse cotidiano de conflitos que passaram a marcar a vida dessa população indígena com a chegada das diversas frentes de exploração na região.

Com o término da Guerra do Brasil, Argentina, Uruguai e o Paraguai (1865-1870), inicia-se na região intensa disputa em torno das terras, ricas em ervais nativos. Tomáz Larangeira conseguiu, por meio do Decreto Imperial, de n. 8799, de 9 de dezembro de 1882, tornar-se o primeiro concessionário legal para a exploração da erva mate nativa, por um período inicial de 10 anos, abrangendo uma área de aproximadamente 5.400.000 hectares. Essa concessão, que abrangeu todo o território indígena, estendeu-se por mais de cinco décadas, indicando a forte influência política dos acionistas da já criada Companhia Matte Larangeira.

A indústria ervateira foi a primeira frente econômica de ocupação do território indígena. Uma série de conflitos com os índios, envolvendo a posse e exploração dos ervais, é verificada tendo, a partir da década de 1940, outras frentes que adentram o território indígena, já em busca de terras para a colonização. Em 1943, a Colônia Agrícola Nacional de Dourados - CAND, retirando cerca de 300 mil hectares de terra da posse indígena. A seguir, vêm os empreendimentos agropecuários e, rapidamente, todo o território indígena é ocupado. Os índios foram progressivamente confinados em áreas de terra reduzidas e obrigados

\footnotetext{
* Mestranda em História pela UFGD e pesquisadora do Centro de Documentação TEKO ARANDU/NEPPI/ UCDB. ** Pesquisador e coordenador do Programa Kaiowá/ Guarani/NEPPI/UCDB. brand@acad.ucdb.br
} 
a abrir mão de parte significativa de seu território. Ficaram sem os recursos imprescindíveis para as suas reais necessidades, o que contribuiu para a fragilização da sua organização social. Esse processo histórico de confinamento, carregado de violências contra esses povos, é pouco conhecido. Os documentos a seguir fazem parte do acervo de microfilmes do Fundo - Serviço de Proteção aos Índios - SPI do Museu do Índio, com cópias disponíveis no Centro de Documentação Teko Arandu ${ }^{1}$ / NEPPI/UCDB, em Campo Grande, MS. Na expectativa que os documentos proporcionem estímulo a novas e mais a profundadas pesquisas, salientamos que o acervo está aberto a pesquisadores de outras instituições.

$9^{a}$ Delegacia Regional

Assunto Índios Cayoas - Perseguição aos referidos índios por parte de Companhia. de Matte

Data: 07/04/1919

Ponta Porá, 7 de abril de 1919

Exmo. Snr. Dr. Adriano Metello

MD. Inspetor dos Índios no Estado de Matto Grosso

Tenho a honra de levar ao vosso conhecimento que, devido as continuas persiguições e correrias de que são victimas os índios Cayoas, residentes neste município, por parte dos empregados da Empresa Matte secundados, muitas vezes por alguma autoridade policial, que, longe de proteger aquelles pobres infelises, quer como conservador da ordem, que por mero espírito humanidade se pelo simples facto de ser tornar agradável aquella Empresa, deixão que livres e ipunemente perseguisem, maltratacem, e até, matacem, algumas vezes aquelles pobres índios.Tendo recebido do [...] Antônio Pedro Vicente, carta nesse sentido, (cuja carta vos remeto). E, movido pelo interesse que sempre me inspira a fraquesa que é velipendiada pela força brutal, tomei a resolução de dirigir-me em excursão, naquellas paragens, com o fim de visu enteirar-me da verdade, e, sendo preciso, dar alguns passos acerca das autoridades competentes, afim de melhorar, n'algum modo, a triste sorte daquelles nossos irmãos, allias dignos de toda proteção, pois que são pacifica dos e trabalhadores; alli chegando, me foram narrados pelos principais índios daquellas localidades, factos de tal natureza, que até as feras movem a compaixão. Me foi referido que de todo modo algum trabalhar socegados; sempre sujeitos, por parte d'aquelle pessoal, a viz esploração, espaneamentos, violações e mortes, não contando, muitas vezes serem enchotados das suas moradias e queimados os seus ranchos. Tudo isto, dicto com aquella linguagem pittoresca e ingênua que tão peculiar é naquella gente desprovida de malicia e subterfugias. Compadecido por tamanho infortúnio, prometilhes interresar-me por elles, juncto a essa Inspetoria, ao Governo, ao 
Senador Pedro Celestino, ao Cel. Rondon, a quem remeto cópias da presente, invocando seus valiosos apoio, a fim de, sendo índios organizados em colônias, dirigidas por um Diretor especialmente nomeado pudesem sob o amparo, da lei, viverem e trabalharem tranquilamente.

A tal, oferecimento resolveram passar-me uma procuração, com amplos poderes competentes, cujo documento junto a esta vos remeto, pedindo-vos a prompta devolução do mesmo.

Uma grande parte desses índios, reside na margem direita do Rio Brilhante desde a barra do córrego São Domingos até a barra do laranja doce, distante este d'aquelle 5 léguas mais ou menos, croqui que juncto vos remeto, tendo o governo reservado uma área de 3.600 hectares de terras para colôgnia de índios, sobre margem do saltinho, conforme o doc 401 de 03/09/1915, os índios allegam a inconveniência de ali morarem, porquanto, em tempo de seca, acharem-se sem água periodicamente e, todos os annos por ser sujeito a secar completamente, ao passo que, se o Governo attendendo esse grande inconveniente, quisesse transferir a concessão das terras reservadas no citado documento para o lugar onde seha-se situado atualmente o aldeiamento do chefe, haveria nessa transferência as seguintes vantagens:

$1^{\circ}$ - o interesse absoluto dos índios em conservar sua querência, que data a mais de século;

$2^{\circ}$ - abundancia de água;

$3^{\circ}$ - bondade que offerece esse rio em ser muito piscoso, epor conseguinte, mais um meio para sua alimentação;

$4^{\circ}$ - a prosimidade dos patrimônios de Dourados e Entre-Rios distantes do $1^{\circ} 3$ e do segundo 4 léguas.

E, finalmente, a navegabilidade do mesmo, que muito contribuirá para o desenvolvimento de uma fuctura colognia.

Oaldeamento que serve de morada do dito chefe de Índios, está situado no logar denominado Cafezal "entre os dois corregos-Sardinha eS. Domingos, distante légua e meia um do outro, dentro da mata deste último, e sobre a margem do Brilhante, formando um potreiro. Agora acontece que esse potreiro foi requerido pelo individuo Bento de Mattos, cujos péssimos precedentes são notoriamente conhecidos; tanto assim que, devido a falças e enganosas informações, dadas pelo seus correligionários ao $\mathrm{Dm}^{\circ}$ Presidente do Estado D. Aquino, foi por este nomeado sub Delegado de Policia do Distrito de Dourados, cargo este que não chegou a exercer, porque $\mathrm{D}$. Aquino, informado posteriormente sobre a verdadeira conducta daquelle individuo demittiu-o immediatamente. Ora, o dito indivíduo, não contente com ter sido sempre maior persiguidor desses Índios, requereu aquelle potreiro para desalojal-os da sua querência, causando-lhe assim innumeros prejuízos.Em vista disso, e na qualidade de procurador de ditos Índios não sendo-me possível protestar aquelle requerimento, por ter-se 
esgotado o praso legal, pesso junto a essa Inspectoria, a sua valiosa cooperação afim [...] fazer abortar aquella Injusta pretenção, perante a Directoria desta [...]

Éjusto e opportuno ponderar-vos que se aquella Repartição attender rav elmente este justo pedido, tudo correrá na maior harmonia [...] mais se por ventura for regeitada, posso assegurar-vos desde já que desse ato irrefletido, resultaria a completa revolta dos índios com o referido Bento de Mattos, propósito este que foi energicamente elles mesmos manifestado. Se, como espero, os índios, forem satisfeitos em desejo, como estou empenhado com o mais vivo interesse sobre o assunto já exposto, resolverei mudar para aquella localidade com minha família, número de 14 pessoas, uma creada e meus velhos paes com o fim de organizar uma grande colognia de Índios; por cujo motivo, espero que essa Inspectoria approveitando as minhas boas disposições, quera honrar-me com as nomeações de Agente da mesma e Director das Colognias indígenas deste município. O número de Índios que calculo aproximadamente deve attingir a mais de 5000 almas; mas, para sabel-o com mais exactidão aproveitando a boa vontade de alguns amigos, mandei proceder um recenciamento em todos os districtos o que breve remeterei, com o fim de maiormente, dar impulso ao meu desideratum appelo para essa Inspectoria, pedindo a nomeação, perante o Governo, de dois professores e uma professora escolares, com o fim de trazerem da instrucção primária dos Índios, o que, sendo aceito, em tempo opportuno indicarei os candidatos. Também aproveito a occasião para, MEDIANTE a vossa intervenção, faser gestão perante D. Aquino, para que, sendo provável, enviar aqui um Padre que queira compartilhar com a ardua missão tendente á benéfica e salutar civilisação de tantos pobres infelizes.

Sem mais e na certesa que essa Dna. Inspectoria queira envidar toda a sua influencia para tão nobre fim, rogo a V. Exa. acceitar os protestos de minha estima e consideração.

(assignado) Antonio Machado Salgueiro

Fonte: Museu do Índio, microfilme 001-A, p. 20 e 21, Rio de Janeiro, 1919. Cópia no Centro de Documentação Teko Arandu/NEPPI/UCDB, Campo Grande, 2007.

\section{Ministério da Guerra}

Circumscriação Militar de Matto Grosso

$11^{\circ}$ Regimento de artilharia montada Quartel em Campo Grande, 10 de setembro de 1919

$\mathrm{N}^{\circ} 102$

Objecto - Apresentando um índio

Ao Ilmo. Snr. Prezidente do Estado de Matto Grosso, O commandante deste regimento.

Sr. Prezidente 
Comprimentando a V. Ex. tenho a honra de apresentar o índio Antonio Pedro Vicente, que havendo solicitado minha intervenção junto aos poderes públicos, afim de ser mantido com sua tribu nas terras, que nas margens do Rio Brilhante e seus affluentes, lhe pertecem, e que estão sendo occupadas por pessoas extranhas, que, para levarem a effeito essa ocupação, lançam mão da força bruta, devastando todas suas plantações.

Nessas condições expuz, como me cumpria, esses fatos ao Snr. Coronel Rondon, solicitando me providencias como o caso exige, tendo recebido a resposta constate no telegrama, cuja cópia junto a este oficio, para que V. Ex. tome conhecimento, tornando como espero, as urgentes e efficazes providencias.

Apresentando a V. Ex. os meus protestos de elevada estima e consideração.

Saudações.

(Assignado) Pedro Cavalcante Albuquerque Leite

Major Commandante Interino.

Fonte: Museu do Índio, microfilme 001-A, p.22, Rio de Janeiro, 1919. Cópia no Centro de Documentação Teko Arandu/NEPPI/UCDB, Campo Grande, 2007.

Ministério da Guerra

Circunscrição Militar de Matto Grosso

$11^{\circ}$ Regimento de artilharia montada Quartel em Campo Grande, 10 de setembro de 1919

$\mathrm{N}^{\circ} 103$

Objecto: Apresentação um índio

Ao Snr Inspector dos índio, o comandante desse regimento.

Snr.Inspector:

Apresento-vos o índios Antônio Pedro Vicente chefe da tribu dos CAINAIS, que devido a falta de garantias, para continuarem a occuparem as terras que lhes foram doadas, por isso que; pessoas extranhas, lançando, como tem lançado, não de força brutas fazem com elle dellas se retirem.

Como esse chefe me procurasse, pedindo providencias, allem do que idêntico pedido já havia feito as diversas auctoridades desse Estado sem que obtivesse resultado algum.

Nessas condições telegraphei, como me cumpri ao Snr. General Rondon, expondo esses factos tendo recebido resposta desse General, em a qual me comunicou que se entendeu com o Snr. Ministro da Agricultura, assim como com o Snr. Prezidente deste Estado, os quaes telegrapharam, a fim de que fossem esses índios mantidos nos terrenos legítimos. 
Cumprindo assim, com o dever do patriotismo vogo-vos a defesa dos direitos desses índios certo que tomareis as necessárias providencias para o fim collimado.

Saudação

Major Comandante interino.

(Assignado) Pedro Cavalcante de Albuquerque Leite -

Fonte: Museu do Índio, microfilme 001-A, p. 26, Rio de Janeiro, 1919. Cópia no Centro de Documentação Teko Arandu/NEPPI/UCDB, Campo Grande, 2007.

Cópia-Telegramma nº 861 - Urgente - Major Pedro Cavalcante de Albuquerque - Campo Grande - Acabo receber vosso telegrama de 27 agradecendo vivamente ao interesse tomastes pela sorte dos índios CAYOAS abitantes rio Brilhante affleuntes ete informo-vos tomei providencias não só junto ministroo Agricultura como Snr. Prezidente Matto Grosso no sentido manter os pobres índios nos terrenos ligítimos donos. Por minha vez peço continuardes dar mesmo apoio deste chefe índios tribu, appelo para vosso alto Posto e austeridade militar região permitiu sustentar em meu nome podeis tomar essa atitude vosso camarada.

RONDON - Rio 30/08/1919

Fonte: Museu do Índio, microfilme 001-A, p.24, Rio de Janeiro, 1919. Cópia no Centro de Documentação Teko Arandu/NEPPI/UCDB, Campo Grande, 2007.

Cópia - telegramma - Campo Grande,

14/09/1919

Snr. Inspector Índios - Corumbá

Chefe índios que aqui me achou depois de haver pedido intervenção autoridade estadoaes e esperado debalde providencias contra invasão terras que lhe eram dados peça monarchia-virg- por paraguayos e brasileiros que lhes destruiu as plantações roubaram seus animaes levando roubo até suas próprias mulheres pediu minha intervenção depois haver se entendido meu antecessor Cel Heitor Borges que pediu providencias uma autoridade Federal-pt-Retirando-se com este official coube-me este vendo-me diariamente assediado por chefe e [...] reclamavam providencias contra invasão seus domínios que foram Governo General Caetano de Albuquerque a terceiros que coapulsavam seus [...] habitanttes a bala, comprehendeis a protecção que devemos dar, se for [...] de para o que tendes recursos, esta immensa população que se domestica [...] valisa concorrendo assim para progresso nossa Pátria - pt - Muitos dos quaes estado selvagem vae prestando sérios serviços exercito que conta seu seio caboclos sabios obedientes cujo unico obstaculo consiste não conhecer nosso [...] tendo se dirigido autoridade policia justiça intendência e autoridade federal constante Campo Grande, tele General Rondon, pedindo sua proteç̧ão por tribu 
que habitam como me communicou seu chefe margens Rio Brilhante e seus affluentes cuja educação bem deveis comprehenderes situação uma autoridade deve fazer valer seus direitos o que levou o tele aquella autoridade que veio em resposta agradecendo meu trabalho colocoume a testa defeza desse fora o qual considera alavanca do futuro nosso Brazil.

Saudações - assi. Pedro de Albuquerque Leite - Major Comandante $11^{\circ} \mathrm{RAM}$

Fonte: Museu do Índio, microfilme 001-A, p. 27, Rio de Janeiro, 1919. Cópia no Centro de Documentação Teko Arandu/NEPPI/UCDB, Campo Grande, 2007.

MINISTÉRIO DA AGRICULTURA INDUSTRIA E COMERCIOSERVIÇO DE PROTEÇÃO AOS INDIOS TELEGRAMA DE SERVIÇO

Corumbá, 19/setembro/1919

Snr. Horta Barbosa

Director proteção Índios

Rio

Em conseqüência missão auxiliar Dantas aqui estiveram dois Índios um Cayoa outro Guarani pt Este de nome Ubiratã letrado trazia uma estatística de grande numero das aldêa de Indios campos sul Estado zona margem direita linha estrada de férreo. Segundo ele entre Guaranis, Terenas e Cayoas foram recenceados dois mil quatrocentos e dezesseis indígenas pt Antonio Pedro Vicente chefe Cayoas que se acha Inspectoria vindo de Campo-Grande informa que estas aldeas são somente metade dos existentes sem levar conta os numerosos índios ainda não pacificados. Cordeaes saudaçoes

Assinado Inspetor Serviço Proteção Índios.

Fonte: Museu do Índio, microfilme 001-A, p.37, Rio de Janeiro, 1919. Cópia no Centro de Documentação Teko Arandu/NEPPI/UCDB, Campo Grande, 2007.

Ministério da Agricultura da Indústria e Commercio - Serviço de Proteção

aos Índios

Telegrama de serviço

Corumbá, 19/setembro/1919

Snr. Horta Barbosa

Director Proteção Índios

Agricultura - Rio

$\mathrm{N}^{\circ} 177$ - Índios Cayoas vindo de Campo Grande não tinham estado Inspectoria pt. Trata-se agora do Beruvichá Antônio Pedro Vicente e seu irmão Santo Ygnácio pt. Habitam Com cerca de quatrocentas pessoas. Immemorialmente terras comprehendidas entre corregos Laranja doce eS. Domingos que desaguam rio Brilhante pt. Aproximadamente 
nove leguas quadradas pt Em tempos de Manoel Caetano Faria de Abuquerque acto $n^{\circ} 401$ de 3/setembro/1917 reservou uma legua quadrada dentro de suas terras para fundação de uma Colonia de Índios pt Em conseqüencia os intrusos pretendem que os índios desocupeh sua posse immemorial ameaçando-os com bando gente armada pt Rogo autorisar-me fazel-os acompanhar um auxiliar que prepare fundação posto bem como recursos necessarios fundação próximo exercício pt. Conte com um dos diaristas por vir para este serviço pt

Cordeaes Saudações

Fonte: Museu do Índio, microfilme 001-A, p.38, Rio de Janeiro, 1919. Cópia no Centro de Documentação Teko Arandu/NEPPI/UCDB, Campo Grande, 2007.

\section{Nota}

${ }^{1}$ Mais informações sobre o acervo do Centro de Documentação visitem o site: www.neppi.org/cedoc.

Recebido em 26 de maio de 2006.

Aprovado para publicação em 7 de junho de 2006. 